\title{
Vitamin D deficiency is associated with inflammatory cytokine concentrations in patients with diabetic foot infection
}

\author{
Shalbha Tiwari ${ }^{1,2}$, Daliparthy Devi Pratyush ${ }^{1,3}$, Sanjeev Kumar Gupta ${ }^{4}$ and Surya Kumar Singh ${ }^{1 *}$ \\ ${ }^{1}$ Department of Endocrinology and Metabolism, Institute of Medical Sciences, Banaras Hindu University, \\ Varanasi 221 005, Uttar Pradesh, India \\ ${ }^{2}$ Chellaram Diabetes Institute, Pune, Maharashtra, India \\ ${ }^{3}$ Department of Biochemistry, All India Institute of Medical Sciences, Bhopal, Madhya Pradesh, India \\ ${ }^{4}$ Department of General Surgery, Institute of Medical Sciences, Banaras Hindu University, \\ Varanasi 221 005, Uttar Pradesh, India
}

(Submitted 2 July 2013 - Final revision received 25 July 2014 - Accepted 30 July 2014 - First published online 21 October 2014 )

\section{Abstract}

Vitamin D has been recognised as a potent immunomodulator and its deficiency is common in different population groups including patients with diabetic foot infection. Diabetic foot infection reflects the altered immune status of the host. As cytokine regulation plays a significant role in infection and wound-healing processes, the present study aimed to evaluate the association between vitamin D status and inflammatory cytokine profiles in patients with diabetic foot infection. The serum concentrations of vitamin D (25-hydroxyvitamin D), IL-1 $\beta$, IL-6, TNF- $\alpha$ and interferon- $\gamma$ (IFN- $\gamma$ ) were measured in 112 diabetic foot infection cases and 109 diabetic controls. Severe vitamin D deficiency (25-hydroxyvitamin D concentration $<25 \mathrm{nmol} / \mathrm{l}$ ) was more common in cases than in controls ( $48 \cdot 2 v$. 20.5\%). Although age, duration of diabetes, $\mathrm{HbA}_{1 \mathrm{C}}$ (glycosylated $\mathrm{Hb}$ ) concentration and BMI were similar, cases had significantly higher concentrations of IL-6 ( $P \leq 0 \cdot 001$ ), IL-1 $\beta(P \leq 0.02)$ and TNF- $\alpha(P \leq 0.006)$ than controls. A significant negative correlation was also observed between 25 -hydroxyvitamin D concentration and circulating concentrations of IL-1 $(r-0.323 ; P \leq 0 \cdot 001)$ as well as IL-6 $(r-0 \cdot 154 ; P \leq 0 \cdot 04)$, but not between

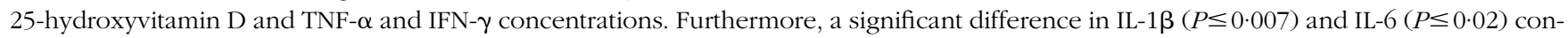
centrations was observed in patients with severe 25-hydroxyvitamin D deficiency compared with patients with 25-hydroxyvitamin D concentration $\geq 25 \mathrm{nmol} / 1$, and this difference was remarkable for TNF- $\alpha$. In conclusion, severe vitamin D deficiency is associated with elevated inflammatory cytokine concentrations in diabetic patients, particularly in those with foot infection. A 25-hydroxyvitamin D concentration value $<25 \mathrm{nmol} / \mathrm{l}$ is suggested as the 'cut-off' for such immunological alterations in patients with diabetes mellitus.

Key words: Vitamin D: Diabetic foot infection: Inflammatory cytokines

In addition to its endocrine role, vitamin $\mathrm{D}$ has been demonstrated to have potent immunomodulatory activities ${ }^{(1,2)}$. It has been shown to be associated with an increased incidence of infections directly or indirectly ${ }^{(3)}$. Vitamin D deficiency is common in the normal population ${ }^{(4,5)}$ and patients with diabetes $^{(6)}$. Diabetic foot infection reflects the altered immune state of the host due to changes in the mediators of the immune function. Cytokines are major mediators of the host's response to infection and thus play an important role in the differentiation of macrophages, eradication of infection and progression of wound-healing process ${ }^{(7,8)}$. An infection triggers inflammatory responses via the release of inflammatory cytokines such as IL-1 $\beta$, IL-6, interferon- $\gamma$ (IFN- $\gamma$ ) and TNF- $\alpha$ or chemokines such as IL- 8 in the host, which are regulated by counter-regulatory mechanisms such as the production of anti-inflammatory cytokines such as IL-10 to avert a hyperinflammatory state necessary for infection control and effective wound healing.

Several known physiological factors such as decreased growth factor production ${ }^{(9-11)}$, angiogenic response ${ }^{(12)}$, and macrophage function ${ }^{(13)}$ and impaired cytokine production ${ }^{(14,15)}$ contribute to wound-healing abnormalities in individuals with diabetes. Moreover, underlying pathological conditions such as hyperglycaemia also disrupt the normal process of cytokine production $^{(16-19)}$. This could further lead to the development of chronic wound where persistent and elevated inflammatory cell activities are considered to be critical ${ }^{(20)}$.

There is a paucity of data on the role of systemic inflammation in diabetic foot infection patients in association with vitamin D status responsible for delayed wound healing.

Abbreviation: IFN- $\gamma$, interferon- $\gamma$.

*Corresponding author: Professor S. K. Singh, fax +91 542 2369222, email sksendocrine@yahoo.com 
It has been proposed that severe vitamin $\mathrm{D}$ deficiency in addition to hyperglycaemia is a risk factor ${ }^{(21)}$ for diabetic foot infection probably via immune dysregulation.

The present study aimed to evaluate the circulating concentrations of IL- $1 \beta$, TNF- $\alpha$, IFN- $\gamma$ and IL- 6 in patients with diabetic foot infection and assess the influence of vitamin $\mathrm{D}$ deficiency on the above-mentioned cytokines.

\section{Subjects and methods}

\section{Subjects}

Patients with diabetic foot infection visiting the diabetic foot clinic and endocrine outpatient unit of the University hospital located at coordinates $25^{\circ} 20^{\prime} 0^{\prime \prime}$ North and $83^{\circ} 0^{\prime} 0^{\prime \prime}$ East were enrolled as cases and diabetic patients without any evidence of infection served as controls in the present study. A detailed clinical history including age, sex, duration of diabetes, and concomitant and anti-diabetic medication usage was recorded in a preset pro forma. Infection was clinically diagnosed by culture positivity and/or higher total leukocyte counts in the presence of other clinical evidences such as fever and signs of inflammation. Bacterial culture and identification were done as described previously ${ }^{(22)}$. The Wagner Diabetic Foot Ulcer Classification System (grade 0: no ulcer, but high-risk foot (e.g. deformities, callus and insensitivity); grade 1: superficial, full-thickness ulcer; grade 2: deeper ulcer, penetrating tendons, without bone involvement; grade 3: deeper ulcer with bone involvement and osteitis; grade 4: partial gangrene (e.g. toes and forefoot); and grade 5: gangrene of the whole foot) was used to grade diabetic foot infection.

Patients exhibiting clinical evidence of vascular insufficiency or taking immune-suppressants, multivitamins and $\mathrm{Ca}$ supplements were excluded from the study. A total of forty healthy subjects also participated voluntarily in the present study. The present study was conducted according to the guidelines laid down in the Declaration of Helsinki, and all procedures involving human subjects were approved by the Institutional Ethics Committee. Written informed consent was obtained from all the participants.

\section{Sample collection}

Blood samples were collected into a plain vial and an EDTAcontaining vial. Sampling was uniform throughout the year without any seasonal variation in the study groups. Coagulated blood was centrifuged at $1800 \mathrm{~g}$ for $10 \mathrm{~min}$. Serum was separated and aliquots of $300 \mu \mathrm{l}$ were stored frozen at $-80^{\circ} \mathrm{C}$ until analysis. Blood samples with the anti-coagulant were used for estimating glycosylated $\mathrm{Hb}\left(\mathrm{HbA}_{1 \mathrm{C}}\right)$ concentration using the DS5 system (Drew Scientific, Inc.) based on ion-exchange chromatography.

\section{Serum 25-hydroxyvitamin D assay}

The serum concentration of 25-hydroxyvitamin D was determined by RIA using a commercial kit (Diasorin) in duplicate according to the manufacturer's protocol. Intra-assay and inter-assay variations (\% CV) were 11.7 and 12.5 respectively.

\section{Cytokine concentration estimation}

The serum concentrations of IL-1 $\beta$, IL-6, TNF- $\alpha$ (Diaclone) and IFN- $\gamma$ (BD Biosciences) were estimated by ELISA using commercial kits according to the manufacturer's instructions. One aliquot was used for the estimation of each cytokine in duplicates. Samples with a test value below the detection limit were excluded from the analysis. The intra-assay and inter-assay CV (\%) were 5.7 and 7.3 for IL-1 $\beta, 4.2$ and 7.7 for IL-6, 3.3 and 9.0 for TNF- $\alpha$, and 3.7 and 6.6 for IFN- $\gamma$, respectively.

\section{Staging of vitamin D deficiency}

Different cut-off values of vitamin D (25-hydroxyvitamin D) were chosen, i.e. $<25 \mathrm{nmol} / 1,<50 \mathrm{nmol} / 1$ and $<75 \mathrm{nmol} / 1$, to evaluate its effect, if any, on the cytokine profiles of the study participants. These cut-off values were similar to those described for Ca homoeostasis ${ }^{(23)}$.

\section{Statistical analysis}

Data are presented as means and standard deviations or as means with their standard errors unless otherwise indicated. Continuous variables that were not normally distributed were logarithmically transformed before analysis. Statistical analysis was conducted using SPSS 16.0 (SPSS, Inc.). Parametric and non-parametric tests were used wherever applicable. Correlation analysis (Spearman) was carried out to determine the association between these inflammatory cytokines and 25-hydroxyvitamin D status in the study population.

\section{Results}

A total of 219 individuals (112 diabetic patients with foot infection (cases) and 107 diabetic patients without infection (controls)) participated in the study. The duration of diabetic foot infection varied from 1 month to 1 year, and the cases enrolled had infection of Wagner's grades 2-4. The mean total leukocyte count in cases was 14971 ( $\mathrm{sE}$ 7556). Bacterial culture revealed the presence of microbial isolates varying from a minimum of one to a maximum of three per case. Escherichia coli was the most common bacterium isolated. The age, duration of diabetes, $\mathrm{HbA}_{1 \mathrm{C}}$ concentration and $\mathrm{BMI}$ of the study participants are summarised in Table 1 . No statistically significant difference was observed in mean age, duration of diabetes, $\mathrm{HbA}_{1 \mathrm{C}}$ concentration and BMI between cases and controls. The mean concentrations of the inflammatory cytokines IL-1 $\beta(P=0 \cdot 02)$, TNF- $\alpha(P=0.006)$ and IL-6 (P=0.001) were significantly higher and that of 25 -hydroxyvitamin $\mathrm{D}(P=0.06)$ was comparatively lower in cases than in controls. The concentrations of IL-1 $\beta$, IL-6, TNF- $\alpha$ and IFN- $\gamma$ were below the detection limit of the assay, i.e. $<7,<8,<2$ and $4.7 \mathrm{pg} / \mathrm{ml}$, respectively, in $95 \%$ of the healthy volunteers and thus data obtained from them could not be included in the analysis.

Vitamin D deficiency (25-hydroxyvitamin D concentration $<50 \mathrm{nmol} / 1$ ) was found in $71.4 \%$ of the diabetic foot infection cases, $61.6 \%$ of the diabetic controls and $48.6 \%$ of the healthy 
Table 1. Comparison of clinical parameters, inflammatory cytokine profiles and 25-hydroxyvitamin D status between cases and controls (Mean values with their standard errors)

\begin{tabular}{|c|c|c|c|c|c|}
\hline & \multicolumn{2}{|c|}{$\begin{array}{l}\text { Diabetic foot } \\
\text { infection cases }\end{array}$} & \multicolumn{2}{|c|}{$\begin{array}{l}\text { Diabetic } \\
\text { controls }\end{array}$} & \multirow[b]{2}{*}{$P$} \\
\hline & Mean & SE & Mean & $\mathrm{SE}$ & \\
\hline Total subjects $(n)$ & \multicolumn{2}{|c|}{112} & \multicolumn{2}{|c|}{107} & \\
\hline Male $(n)$ & \multirow{2}{*}{\multicolumn{2}{|c|}{$\begin{array}{l}76 \\
36\end{array}$}} & \multirow{2}{*}{\multicolumn{2}{|c|}{$\begin{array}{l}72 \\
35\end{array}$}} & \\
\hline Female $(n)$ & & & & & \\
\hline Age (years) & $53 \cdot 6$ & $1 \cdot 0$ & $51 \cdot 9$ & 1.0 & 0.2 \\
\hline $\begin{array}{l}\text { Duration of } \\
\text { diabetes (years) }\end{array}$ & $6 \cdot 7$ & 0.5 & $6 \cdot 5$ & 0.7 & 0.8 \\
\hline $\mathrm{HbA}_{1 \mathrm{C}}(\%)$ & $9 \cdot 7$ & 0.25 & $9 \cdot 0$ & 0.28 & 0.054 \\
\hline BMI $\left(\mathrm{kg} / \mathrm{m}^{2}\right)$ & $23 \cdot 6$ & 0.5 & 24.4 & 0.4 & 0.2 \\
\hline Vitamin D (nmol/l) & $40 \cdot 2$ & 3.7 & $49 \cdot 4$ & $3 \cdot 2$ & 0.06 \\
\hline IL-6 (pg/ml) & $128 \cdot 7$ & $7 \cdot 4$ & $87 \cdot 3$ & 9.0 & 0.001 \\
\hline IL-1 $\beta(p g / m l)$ & $101 \cdot 5$ & $20 \cdot 8$ & $49 \cdot 3$ & $10 \cdot 8$ & 0.02 \\
\hline TNF- $\alpha(\mathrm{pg} / \mathrm{ml})$ & $182 \cdot 3$ & $20 \cdot 8$ & $96 \cdot 5$ & $22 \cdot 9$ & 0.006 \\
\hline $\mathrm{IFN}-\gamma(\mathrm{pg} / \mathrm{ml})$ & $18 \cdot 1$ & $3 \cdot 2$ & $13 \cdot 7$ & 1.5 & 0.2 \\
\hline
\end{tabular}

$\mathrm{HbA}_{1 \mathrm{C}}$, glycated $\mathrm{Hb}$; IFN- $\gamma$, interferon- $\gamma$.

volunteers, but severe deficiency (25-hydroxyvitamin D concentration $<25 \mathrm{nmol} / \mathrm{l}$ ) was most common in diabetic foot infection cases than in diabetic controls and healthy volunteers (48.2, 20.5 and $7.6 \%$, respectively) (Fig. 1). In both cases and controls, 25-hydroxyvitamin D concentration was found to be significantly negatively correlated with IL-1 $\quad(r-0.323 ; \quad P \leq 0 \cdot 001)$ (Fig. $2(\mathrm{a}))$ as well as IL-6 $(r-0.154 ; P=0.04)$ concentrations (Fig. 2(b)) and moderately correlated with TNF- $\alpha$ concentration $(r-0.102 ; P=0.07)$ (Fig. 2(c)), but not with IFN- $\gamma$ concentration $(r-0.009$; $P=0 \cdot 9$ ). Independent correlation analysis revealed a nonsignificant negative correlation between vitamin $\mathrm{D}$ and cytokine concentrations in the study participants, except for IL-1 $\beta$, which exhibited a significant correlation independently in cases and controls (Table 2). Patients with 25-hydroxyvitamin D concentration $<25 \mathrm{nmol} / 1$ had significantly higher concentrations of IL-1 $\beta$ and IL- 6 than those with 25-hydroxyvitamin $\mathrm{D}$ concentration $\geq 25 \mathrm{nmol} / 1$. Despite remarkable elevation in the corresponding concentration of TNF- $\alpha$ (185.0 (SE 26.1) v. 122.6 ( $\operatorname{se~19.2);~} P=0.05$ ), the difference did not reach statistical significance in these subgroups (Table 3). There was no difference in IFN- $\gamma$ concentration. No significant correlation was observed between cytokine concentrations and 25-hydroxyvitamin D cut-off value of $50 \mathrm{nmol} / 1$.

\section{Discussion}

In the present study, patients with diabetic foot infection served as a model for significant immunological defects owing to the pathological combination of hyperglycaemia and infection. The concentrations of inflammatory cytokines were significantly elevated in patients with diabetic foot infection than in diabetic controls. Our findings were similar to those reported by Weigelt et $a l^{(24)}$, who showed non-random up-regulation of several acute-phase proteins, cytokines and chemokines such as high-sensitivity C-reactive protein and IL-6 in patients with diabetic foot infection. Such perturbations were not observed for IFN- $\gamma$, the concentration of which increases in response to intracellular invasion of bacteria such as Mycobacterium tuberculosis and/or during autoimmune destruction conditions such as type 1 diabetes mellitus.

The variables known to influence cytokine production such as age and $\mathrm{BMI}^{(25)}$, duration of diabetes ${ }^{(26)}$ and glycaemic status ${ }^{(27)}$ were similar between the two groups in the present study. Interestingly, there was a negative correlation between cytokine and vitamin D concentrations. Similarly, findings from another study have shown that 1,25-dihydroxyvitamin $\mathrm{D}_{3}$ down-regulates the expression of the inflammatory cytokines TNF- $\alpha$, IL-6 and IL-1 $\beta^{(28)}$ and suppresses IFN$\gamma$-mediated macrophage activation $^{(1)}$. In a double-blind, randomised, placebo-controlled trial in congestive heart failure (CHF) patients, vitamin D supplementation was found to reduce the inflammatory cytokine milieu ${ }^{(29)}$. However, findings reported by Clende et al. ${ }^{(30)}$ in healthy women with variable cut-off values of 25-hydroxyvitamin D were in contrast to the above findings and failed to demonstrate any relationship with inflammatory cytokines. The concentrations of cytokines are influenced by several physiological factors, and we proposed that vitamin D could be one of them. There is no definite cutoff value defined for cytokines that could help differentiating healthy and diseased states or indicating the severity of the disease; thus, to study the association between vitamin D status and cytokine concentrations, a correlation analysis using Spearman's correlation was carried out in the present study.

Vitamin D deficiency and its various implications have been studied in patients with diabetes ${ }^{(6)}$. In the present study, severe vitamin D deficiency was more common in patients with diabetic foot infection than in diabetic controls. The photoconversion of 7-dehydrocholesterol to pre-vitamin $\mathrm{D}_{3}$ and its photoproducts is maximal between 11.00 and 14.00 hours throughout the year in India ${ }^{(31)}$. Rural sick patients spend more time in the morning for their hygiene-related care such as outdoor bath and oil massage, which is a common practice in the rural Indian population. Despite ample exposure to sun, patients with diabetic foot infection were found to be severely vitamin D deficient compared with controls in the present study. Although controls

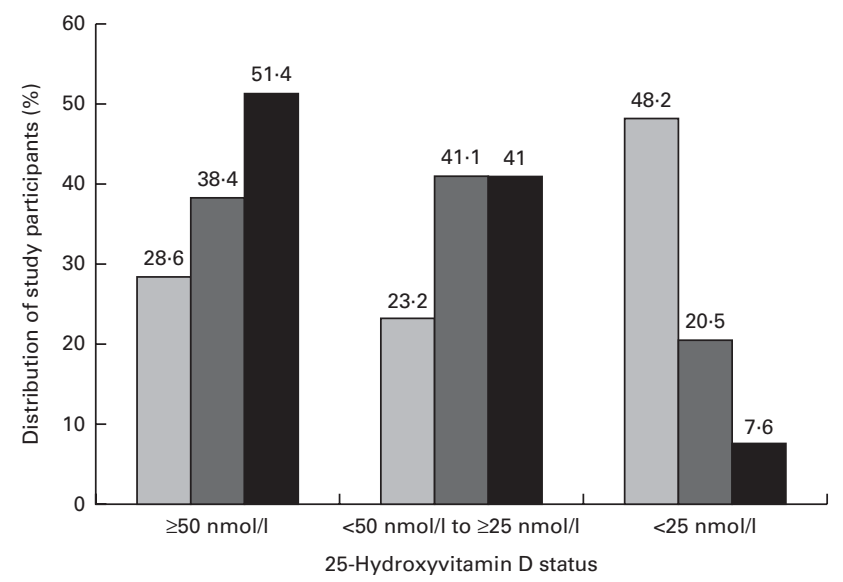

Fig. 1. Distribution of study participants (\%) with respect to vitamin D status. $\square$, Diabetic foot infection; $\square$, diabetic control; $\mathbf{\square}$, healthy control. 

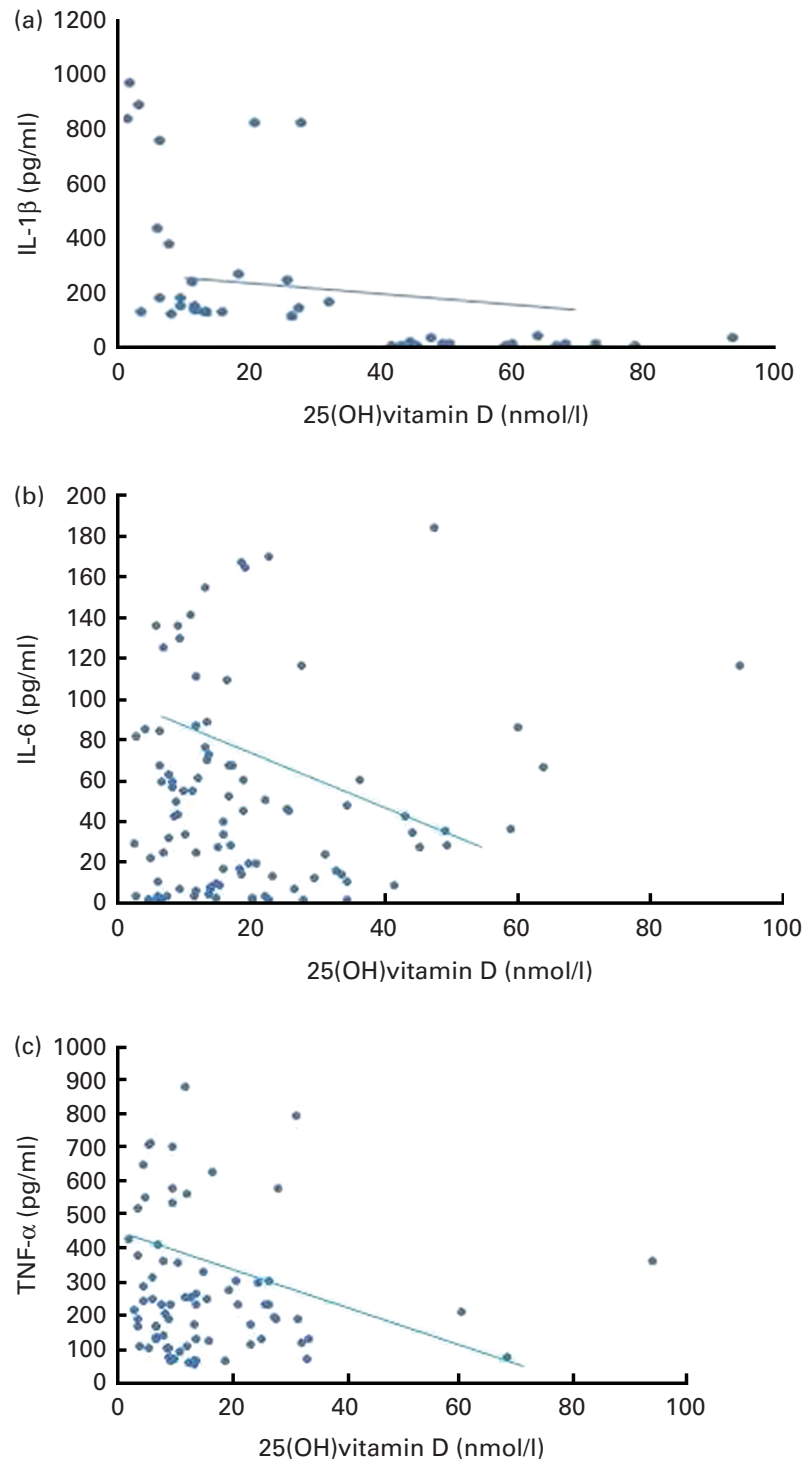

Fig. 2. Correlation between 25 -hydroxyvitamin $D(25(\mathrm{OH})$ vitamin $\mathrm{D})$ and cytokines: (a) IL-1 $\beta(r-0.323, P \leq 0.001)$, (b) IL-6 $(r-0.154, P=0.04)$ and (c) TNF- $\alpha(r-0.102, P=0.07)$. A colour version of this figure can be found online at http://www.journals.cambridge.org/bjn

worked indoors, we speculate that these patients may have had higher non-occupational sun exposure than their diabetic foot infection counterparts during the time periods of the day when cutaneous vitamin D synthesis is greatest, which is after noon. Other factors that could be responsible for the difference in vitamin D status between controls and diabetic foot infection patients include skin pigmentation, clothing pattern and sunscreen usage ${ }^{(32)}$. We did not assess these variables in the present study as we aimed to assess the association or effect of vitamin D deficiency with/on the immune function of such patients irrespective of their aetiology.

In our previous study ${ }^{(21)}$, we have shown vitamin $\mathrm{D}$ concentration of $10 \mathrm{ng} / \mathrm{ml}(25 \mathrm{nmol} / \mathrm{l})$ to be a possible risk factor $(\mathrm{OR}=4)$ for diabetic foot infection using logistic regression analysis with a proposition that it might result in immune dysregulation. In the present study, we chose this cut-off value to assess the difference in immune status defined by cytokine concentrations at this risk point and found that there was a significant difference in the concentrations of IL- 1 and IL- 6 in patients with severe vitamin D deficiency (serum 25-hydroxyvitamin D concentration $<25 \mathrm{nmol} / \mathrm{l}$ ) in comparison with patients with serum 25 -hydroxyvitamin D concentration $\geq 25 \mathrm{nmol} / 1$, which substantiated our previous finding. The difference was also notable for TNF- $\alpha$. Our finding was similar to that reported by another study, in which $25(\mathrm{OH})$ vitamin $\mathrm{D}$ concentration $<25 \mathrm{nmol} / \mathrm{l}$ was found to be associated with higher baseline concentrations of TNF- $\alpha$, IL- 6 and IL- 8 in tuberculosis-immune reconstitution inflammatory syndrome patients ${ }^{(33)}$

The results of the present study showed that elevated cytokine responses occur as a consequence of vitamin D deficiency in patients with diabetic foot infection. The results also served to redefine the cut-off value of 25-hydroxyvitamin D deficiency for healthy and diseased populations. Based on these results, we suggest a 25-hydroxyvitamin D concentration value $<25 \mathrm{nmol} / 1$ to be the cut-off for unfavourable immunological alterations. Studies including various other immunological parameters would provide evidence for this distinctive hypothesis and these results in the future.

Vitamin D and cytokines are intrinsic factors, whereas infection is an extrinsic factor that influences cytokine production in the host. We tried to identify vitamin D deficiency as an additional factor contributing to immune dysfunction in a particular group of diabetic patients, i.e. with foot infection having a glycaemic status similar to that of diabetic patients without foot infection. The negative association between vitamin D and cytokine concentrations in diabetic patients was found to be disrupted when cytokine responses escalated in response to foot infection. The crosssectional design of the present study is a limitation and therefore the results need to be substantiated by an ex vivo experiment on immune cell responses to vitamin D stimulation and cytokine production.

Table 2. Correlation between vitamin $\mathrm{D}$ and cytokine concentrations in cases, controls and total population

\begin{tabular}{|c|c|c|c|c|c|c|c|c|c|}
\hline \multirow[b]{2}{*}{ Vitamin D } & \multicolumn{3}{|c|}{ DFI cases } & \multicolumn{3}{|c|}{$\mathrm{DC}$} & \multicolumn{3}{|c|}{ Total } \\
\hline & $n$ & $r$ & $P$ & $n$ & $r$ & $P$ & $n$ & $r$ & $P$ \\
\hline IL-1 $\beta$ & 90 & -0.234 & 0.02 & 106 & -0.375 & 0.000 & 196 & -0.323 & $\leq 0.001$ \\
\hline IL-6 & 99 & -0.095 & 0.3 & 72 & -0.087 & 0.4 & 171 & -0.154 & 0.04 \\
\hline TNF- $\alpha$ & 86 & 0.09 & 0.4 & 60 & -0.257 & 0.04 & 146 & $-0 \cdot 102$ & 0.07 \\
\hline IFN- $\gamma$ & \multicolumn{9}{|c|}{ No significant correlation in any group } \\
\hline
\end{tabular}

DFI, diabetic foot infection; DC, diabetic control; IFN- $\gamma$, interferon- $\gamma$. 
Table 3. Comparison of inflammatory cytokine concentrations in subjects with and without severe vitamin $D$ deficiency

(Mean values with their standard errors)

\begin{tabular}{|c|c|c|c|c|c|}
\hline \multirow[b]{3}{*}{ Parameters } & \multicolumn{5}{|c|}{ Vitamin $D(\mathrm{nmol} / \mathrm{l})$} \\
\hline & \multicolumn{2}{|c|}{$<25$} & \multicolumn{2}{|c|}{$\geq 25$} & \multirow[b]{2}{*}{$P$} \\
\hline & Mean & SE & Mean & $\mathrm{SE}$ & \\
\hline Age (years) & $52 \cdot 1$ & $8 \cdot 7$ & 52.5 & 11.9 & NS \\
\hline $\mathrm{BMI}\left(\mathrm{kg} / \mathrm{m}^{2}\right)$ & $24 \cdot 2$ & 3.9 & 24.9 & 3.8 & NS \\
\hline $\mathrm{HbA}_{1 \mathrm{C}}(\%)$ & $9 \cdot 2$ & $2 \cdot 2$ & $9 \cdot 7$ & $3 \cdot 2$ & NS \\
\hline IL-6 (pg/ml) & $127 \cdot 1$ & 9.3 & 99.4 & $7 \cdot 6$ & 0.02 \\
\hline $\mathrm{IL}-1 \beta(\mathrm{pg} / \mathrm{ml})$ & 113.5 & $28 \cdot 2$ & $50 \cdot 6$ & 9.1 & 0.007 \\
\hline TNF- $\alpha(\mathrm{pg} / \mathrm{ml})$ & $185 \cdot 0$ & $26 \cdot 1$ & $122 \cdot 6$ & $19 \cdot 2$ & 0.05 \\
\hline IFN- $\gamma(\mathrm{pg} / \mathrm{ml})$ & $15 \cdot 8$ & 3.9 & 14.4 & 1.6 & NS \\
\hline
\end{tabular}

In conclusion, diabetic foot infection represents a state where inflammatory responses occur in an uncontrolled manner owing to the pathological bad trio of hyperglycaemia, wound and infection. Vitamin D deficiency escalated inflammatory cytokine release in patients with diabetic foot infection, particularly when its serum concentrations were very low. Therefore, we suggest a 25 -hydroxyvitamin D concentration value $<25 \mathrm{nmol} / 1$ as the 'cut-off' for unfavourable immunological alterations in patients with diabetes mellitus. Furthermore, we propose atypical interplay of inflammatory cytokines and vitamin D to have clinical implications for patients with diabetic foot infection.

\section{Acknowledgements}

The authors thank Mr Rammohan Rayicherela, former Biostatistician at Banaras Hindu University and Senior Associate Biostatistics at Cognizant Technology Solutions, for helping with the statistical analysis. They also thank Ms Spandana Birajdar, Sub-editor, Diabetes Health Magazine, Chellaram Diabetes Institute, Pune, India, for language corrections.

The present study was funded by the Indian Council of Medical Research (ICMR), New Delhi, India, in the form of a grant (IRIS ID no. ICMR/RHN/2008-04670) to S. K. S. for conducting the study. The ICMR has no role in the design and analysis of the study and in the writing of the article S. T. and D. D. P. thank the University Grant Commission (UGC), New Delhi, India, for providing Research Fellowships.

The authors' contributions are as follows: S. T. collected the data, carried out the experiments, analysed the data, and drafted the manuscript; D. D. P. collected and compiled the data and helped with the experiments and manuscript preparation; S. K. G. provided the samples and edited the manuscript; S. K. S. designed the study, gained support for conducting the study, provided the samples and resources for the study and edited the manuscript. Part of the study has been presented in ENDO 2011 meeting by S. K. S.

The authors declare no potential conflicts of interest.

\section{References}

1. Helming L, Bose J \& Ehrchen J (2005) 1 1 ,25-Dihydroxyvitamin $D_{3}$ is a potent suppressor of interferon $\gamma$-mediated macrophage activation. Blood 106, 4351-4358.
2. Van EE \& Mathieu C (2005) Immunoregulation by 1,25dihydroxyvitamin $\mathrm{D}_{3}$ : basic concepts. I Ster Biochem Mol Biol 97, 93-101.

3. James RS, Paolo DP, Ralph JC, et al. (2010) Serum 25-hydroxyvitamin D and the incidence of acute viral respiratory tract infections in healthy adults. PLOS ONE 5, 11088.

4. Goswami R, Gupta N, Goswami D, et al. (2000) Prevalence and significance of low 25-hydroxyvitamin D concentrations in healthy subjects in Delhi. Am J Clin Nutr 72, 472-475.

5. Singh SK, Prakash V, Tiwari S, et al. (2011) Summer and winter prevalence of vitamin D deficiency of young resident doctors in North India. Nutr Diet 68, 280-284.

6. Mattila C, Knekt P, Mannisto S, et al. (2007) Serum 25-hydroxyvitamin D concentration and subsequent risk of type 2 diabetes. Diabetes Care 30, 2569-2570.

7. Iacopino AM (1995) Diabetic periodontitis: possible lipidinduced defect in tissue repair through alteration of macrophage phenotype and function. Oral Dis 1, 214-229.

8. Oncul O, Yildiz S, Gurer US, et al. (2007) Effect of the function of polymorphonuclear leukocytes and interleukin-1 $\beta$ on wound healing in patients with diabetic foot infections. J Infect 54, 250-256.

9. Galkowska H, Wojewodzka U \& Olszewski WL (2006) Chemokines, cytokines, and growth factors in keratinocytes and dermal endothelial cells in the margin of chronic diabetic foot ulcers. Wound Repair Regen 14, 558-565.

10. Goren I, Muller E, Pfeilschifter J, et al. (2006) Severely impaired insulin signaling in chronic wounds of diabetic ob/ob mice: a potential role of tumor necrosis factor- $\alpha$. Am J Pathol 168, 765-777.

11. Falanga V (2005) Wound healing and its impairment in the diabetic foot. Lancet 366, 1736-1743.

12. Geerlings SE \& Hoepelman AIM (1999) Immune dysfunction in patients with diabetes mellitus (DM). FEMS Immunol Med Microbiol 26, 259-265.

13. Kazuichi M, Jun A, Masaaki I, et al. (2007) Decreased macrophage number and activation lead to reduced lymphatic vessel formation and contribute to impaired diabetic would healing. Am J Pathol 170, 1178-1191.

14. Galiano RD, Tepper OM, Pelo CR, et al. (2004) Topical vascular endothelial growth factor accelerates diabetic wound healing through increased angiogenesis and by mobilizing and recruiting bone marrow-derived cells. Am J Pathol 164, 1935-1947.

15. Peleg AY, Weerarathna T, McCarthy JS, et al. (2007) Common infections in diabetes: pathogenesis, management and relationship to glycaemic control. Diabetes Metab Res Rev 23, 3-13.

16. Naguib G, Al-Mashat H, Desta T, et al. (2004) Diabetes prolongs the inflammatory response to a bacterial stimulus through cytokine dysregulation. J Investig Dermatol 123, $87-92$.

17. Geerlings S, Brouwer E, Van KK, et al. (2000) Cytokine secretion is impaired in women with diabetes mellitus. Eur J Clin Invest 30, 995-1001.

18. Mishima Y, Kuyanma A, Tada A, et al. (2001) Relationship between serum tumor necrosis factor- $\alpha$ and insulin resistance in obese men with type 2 diabetes mellitus. Diabetes Res Clin Pract 52, 119-123.

19. Brem H \& Tomic-Canic M (2007) Cellular and molecular basis of wound healing in diabetes. J Clin Invest 117, 1219-1222.

20. Agren MS, Eaglstein WH, Ferguson MW, et al. (2000) Causes and effects of the chronic inflammation in venous leg ulcers. Acta Derm Venereol 210, 3-17. 
21. Tiwari S, Pratyush DD, Gupta B, et al. (2013) Prevalence and severity of vitamin D deficiency in patients with diabetic foot infection. Br J Nutr 109, 99-102.

22. Tiwari S, Pratyush DD, Dwivedi A, et al. (2012) Microbiological and clinical characteristics of diabetic foot infections in northern India. J Infect Dev Ctries 6, 329-332.

23. Holick MF, Binckley NC, Bischoff-Ferrari HA, et al. (2011) Evaluation, treatment, and prevention of vitamin D deficiency: an Endocrine Society Clinical Practice Guideline. J Clin Endocrinol Metab 96, 1911-1930.

24. Weigelt C, Rose B, Poschen U, et al. (2009) Immune mediators in patients with acute diabetic foot syndrome. Diabetes Care 32, 1491-1496.

25. Himmerich H, Fulda S, Linseisen J, et al. (2006) TNF- $\alpha$, soluble TNF receptor and interleukin- 6 plasma levels in the general population. Eur Cytokine Netw 17, 196-201.

26. U.K. Prospective Diabetes Study Group (1995) U.K. Prospective Diabetes Study 16 - overview of 6 years' therapy of type II diabetes: a progressive disease. Diabetes 44, 1249-1258 (Erratum in Diabetes 1996; 45: 1655).

27. Maedler K, Sergeev P, Ris F, et al. (2002) Glucose-induced $\beta$-cell production of IL-1 $\beta$ contributes to glucotoxicity in human pancreatic islets. J Clin Invest 110, 851-860.
28. Giulietti A, Etten EV, Overbergh LK, et al. (2007) Monocytes from type 2 diabetic patients have a pro-inflammatory profile. 1,25-Dihydroxyvitamin $\mathrm{D}_{3}$ works as anti-inflammatory. Diabetes Res Clin Pract 77, 47-57.

29. Schleithoff SS, Zittermann A, Tenderich G, et al. (2006) Vitamin D supplementation improves cytokine profiles in patients with congestive heart failure: a double-blind, randomized, placebo-controlled trial. Am J Clin Nutr 83, 754-759.

30. Clendenen TV, Koenig KL, Arslan AA, et al. (2011) Factors associated with inflammation markers, a cross-sectional analysis. Cytokine 56, 769-778.

31. Harinarayan CV, Holick MF, Prasad UV, et al. (2013) Vitamin $\mathrm{D}$ status and sun exposure in India. Dermato-Endocrinology 5, 130-141.

32. McCarty CA (2008) Sunlight exposure assessment: can we accurately assess vitamin $\mathrm{D}$ exposure from sunlight questionnaires? Am J Clin Nutr 87, 1097S-1101S.

33. Conesa-Botella A, Meintjes G, Coussens AK, et al. (2012) Corticosteroid therapy, vitamin D status, and inflammatory cytokine profile in the HIV-tuberculosis immune reconstitution inflammatory syndrome. Clin Infect Dis 55, 1004-1011. 